\title{
Growth Patterns of Two Chinese Native Goose Breeds
}

\section{-Author(s)}

Ibtisham $\mathrm{F}^{\prime}$
An $\mathrm{L}^{\prime}$
Li T'
Niu $\mathrm{Y}^{\prime}$
Xiao $\mathrm{M}^{\prime}$
Zhang $\mathrm{L}^{\prime}$
Jia $\mathrm{R}^{\prime}$

Agricultural College, Guangdong Ocean University, Zhanjiang 524088, P.R. China

\section{Mail Address}

Corresponding author e-mail address Li Zhang and Professor Rumin Jia

East to Huguangyan, Zhanjiang 524088, P.R China - Agricultural College, Guangdong

Ocean University

Tel: $\quad$ +867592383247

Email: zhangli761101@163.com zjoujrm@163.com

\section{-Keywords}

Goose, Chinese native breeds, Body Weight, Growth Curve, nonlinear models.

\section{ABSTRACT}

To study the development rules of Chinese native geese, two breeds, Shitou and Sichuan White geese were analyzed from 0 to 12 weeks of age. The growth curves were fitted with commonly used four kinds of nonlinear models (Logistic, Gompertz, Von Bertalanffy and Richards). The results showed that the growth curves were appropriately fitted with all four models but the Logistic and Richards both had the best fitting with growth curve $\left(R^{2}>0.99\right)$. Analyzing the fitting parameters of the Logistic and Richards, we found that male Shitou had the highest adult body weight while Sichuan White female had the lowest weight. In Shitou breed, Shape parameter Predicted with Richards model was corresponded with Gompertz curve, while in Sichuan breed it was in between Gompertz and Bertalanffy. Growth parameters predicted with Logistic model was much more closed to observed value as compared others. So overall logistic was the best model to analyze the growth curve in Chinese native goose and Shitou goose had excellent growth performance when compared to Sichuan White.

\section{INTRODUCTION}

Goose is one of the most important economic poultry around the world because of the growing demand of the human population. At the present time, goose farming is economically important both in Asia and Central Europe. Geese meat is rich with nutrition containing protein, fat, vitamin A, vitamin B, niacin and sugar, and its meat is widely used as a healthy food due to its high protein, low fat and low cholesterol Stevenson et al. (1989). Not only is the meat favorably healthy to humans, it's by-products are also used to prepare other human daily life products. The bones and feather stalks can be processed into powder and have high digestibility as a protein feed, and can be used as fish meal replacement Ding et al. (2014). The biggest goose producer is China with $94 \%$ of the world production. Until now, twenty-six Chinese domestic goose breeds have been identified and domestic goose breeds have better performance due to its better adaptability to extensive management, better immunity to diseases, a higher reproduction rate, and better meat quality Zhu et al. (2010). Growth is the increase in body size per unit of time Rizzi et al. (2013) and growth performance is one of the main issues in the living organism, genetics and environmental condition of living organism can influence growth. Geese are among the fastest-growing avian species commonly raised for meat. Prediction of growth pattern is an important factor that contributes to the profitability of an operation in poultry production. Many factors can affect the profitability like feed type and its cost, health status of birds and environmental condition for growth, Geng et al. (2016). That's why predictions of growth when the birds are ready for 
sale are important factors to increase the economy of poultry operations, Lin et al. (2015). Growth function mathematics can help in management and efficiency of animal and birds, in addition, it can also be used to determined the nutrient utilization and daily diet requirement, Darmani Kuhi et al. (2010). Growth trend defines periodic changes of underlying characteristics, and unfortunately, no one can measure continuously most of these growth, therefore, it is preferable to use mathematical functions, Şengül \& Kiraz (2005).

Developmentalists are much interested to understand the developmental change processes and nonlinear growth curves, because the defining characteristics of the growth process, such as initial levels, rates of change during growth spurts, and asymptotic levels can be estimated. Growth curves are used to express the time-dependent nonlinear variation of live weight through a mathematical function, and the generated equations can be used to predict the expected weight of a group of animals at a certain age, Kim et al. (2016). Some existing growth models can be used to determine the age-live weight relationship of animals. Growth functions have three categories, $1^{\text {st }}$ those that only represent diminishing returns behavior, $2^{\text {nd }}$ those describing smooth sigmoid behavior with a fixed point of inflection and $3^{\text {rd }}$ those encompassing sigmoid behavior with a variable point of inflection. Each growth curve has different characteristics and different mathematical limitations. Four nonlinear growth models: Logistic, Gang \& Zhen (1997), Gompertz, Mignon-Grasteau et al. (1999), Bertalanffy, Schofield et al. (2013), and Richards, Knízetová et al. (1995), equations are often used to fit the growth curve of poultry. The von Bertalanffy, Gompertz, and logistic models have a fixed growth form which inflection points at about 30,37 , and $50 \%$ of the asymptote, respectively while Richards model, which has a variable point of inflection specified by the shape parameter (d), Aggrey (2002). Shape parameter has the greater propensity to change in response to environmental changes than the asymptotic weight, so, it may be used to study the effects of environmental stress on growth, Wang et al. (2012). This reasoning inherently implies that growth models with fixed shapes may not contribute to the understanding of the effects of factors such as dietary and environmental changes on growth, Liu et al. (2015). The non-linear investigation of the growth process has some advantages, like it can help in estimating the relationship between feed requirements and body weight, Grimm et al. (2011).
There have been quite few studies that have been performed with respect to growth analysis in Chinese local goose. The objective of the current study was to estimate and compare the growth curve parameters of Shi Tou Goose (ST) and Si Chuan White Goose (SCW) with Bertalanffy, Gompertz, Logistic and Richards models. Growth parameters are important tools for selection criteria, feed management during the production period and to know the slaughter weight. Further examine, whether there are breed differences in the growth parameters of two geese.

\section{MATERIALS AND METHODS}

\section{Ethics statement}

This study was approved by Animal Care Committee of Guangdong Ocean University (Zhanjiang, Guangdong, People's Republic of China). The animals involved in this study were humanely sacrificed as necessary to ameliorate suffering.

\section{Birds and environmental conditions}

Male (40) and female (40) individuals from each local geese breed of China, ST and SCW, were compared. The birds were reared from $1 \mathrm{~d}$ to $84 \mathrm{~d}$ of life. The geese were maintained under semi-intensive system of rearing. All birds were reared on litter floor, with an additional outdoor watering area. Feed and water were provided ad libitum. The birds were fed a starter diet (18\% CP, 11.8MJ ME/kg, 1.0\% Ca and $0.5 \% \mathrm{P})$ from 0 to $21 \mathrm{~d}$, and a grower diet (15\% CP, $12.2 \mathrm{MJ} \mathrm{ME} / \mathrm{kg}, 0.9 \% \mathrm{Ca}$ and $0.5 \% \mathrm{P}$ ) from 22 to $84 \mathrm{~d}$. In addition to that, the green grasses were fed all day. The photoperiod varied from 12 to $14 \mathrm{~h}$ of natural light. The body weight was measured on the first day and after that every week up-to-the $12^{\text {th }}$ week of growth

\section{Statistical analysis}

Live weight of all birds related to their age was used to estimate the Growth Parameter. Widely used nonlinear growth models, Gompertz, Logistic, Bertalanffy and Richards were fitted to estimate the mean agelive weight relationship and were compared to find the optimum growth model for different sexes of geese. For statistical analysis SPSS version 19 was used and the coefficients of determination ( $R^{2}$ values) were compared to find the optimum growth model. The age (days) and the weight (grams) at inflection point were determined. The mathematical relations of these models are listed in Table 1. 
Table 1 - Four kinds of growth curve models and the parameters

\begin{tabular}{llll}
\hline Model & Equation & Age $($ day $)$ at Inflection (IPA) & Weight $(\mathrm{g})$ at inflection (IPW) \\
\hline Logistic & $\mathrm{Y}=\mathrm{A} /(1+\mathrm{Be}-\mathrm{kt})$ & $(\ln \mathrm{B}) / \mathrm{k}$ & $\mathrm{A} / 2$ \\
Gompertz & $\mathrm{Y}=\mathrm{Ae}-\mathrm{B} \exp (-\mathrm{kt})$ & $(\operatorname{lnB}) / \mathrm{k}$ & $\mathrm{A} / \mathrm{e}$ \\
Bertalanffy & $\mathrm{Y}=\mathrm{A} /(1-\mathrm{Be}-\mathrm{kt}) 3$ & $(\ln 3 \mathrm{~B}) / \mathrm{k}$ & $8 \mathrm{~A} / 27$ \\
Richards & $\mathrm{Y}=\mathrm{A} /(1+\exp (\mathrm{B}-\mathrm{kt}) \wedge(1 / \mathrm{d}))$ & $-\mathrm{k}-1 \ln (\mathrm{d} / \operatorname{expB})$ & $\mathrm{A} /(\mathrm{d}+1) 1 / \mathrm{d}$ \\
\hline
\end{tabular}

A: Maximum body weight, $k$ : Transient growth rate, B: Parameter, t: Weekly age d: Shape Parameter

\section{RESULTS}

\section{Growth Curve}

Growth curve model is subject to the changes in each stage of growth and development, and ideal growth curve model is helpful to guide the production practice. According to our finding both ST and SCW breeds male and female had the same growth rate before 6 weeks of age after that male had more growth rate than the female. In both breeds males had more weight than females and between male,

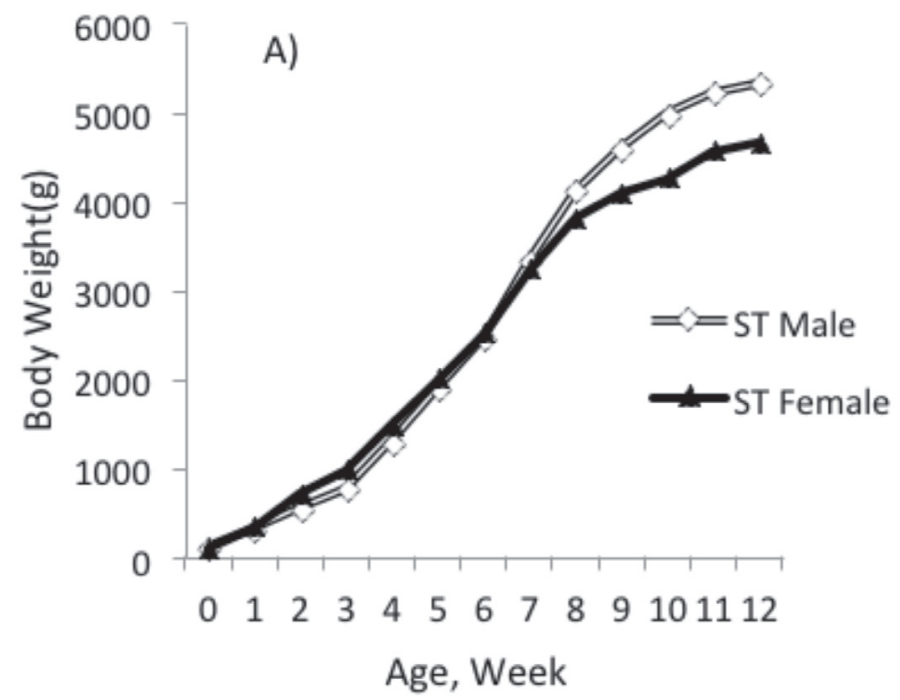

ST male had more weight than SCW male goose, cumulative growth curve are presented in figure 1 . ST Male and Female growth curve are presented in figure $2 \mathrm{~A}$ and $\mathrm{B}$ respectively, the growth curve was coherent, and during the first six weeks the growth rate was fast and after this the growth rate decreased gradually. In SCW as in ST goose the growth rate was fast during the first 6 weeks and then decreased gradually in the next weeks. Growth curve of SCW male and female are presented in figure $3 \mathrm{~A}$ and $\mathrm{B}$ respectively.

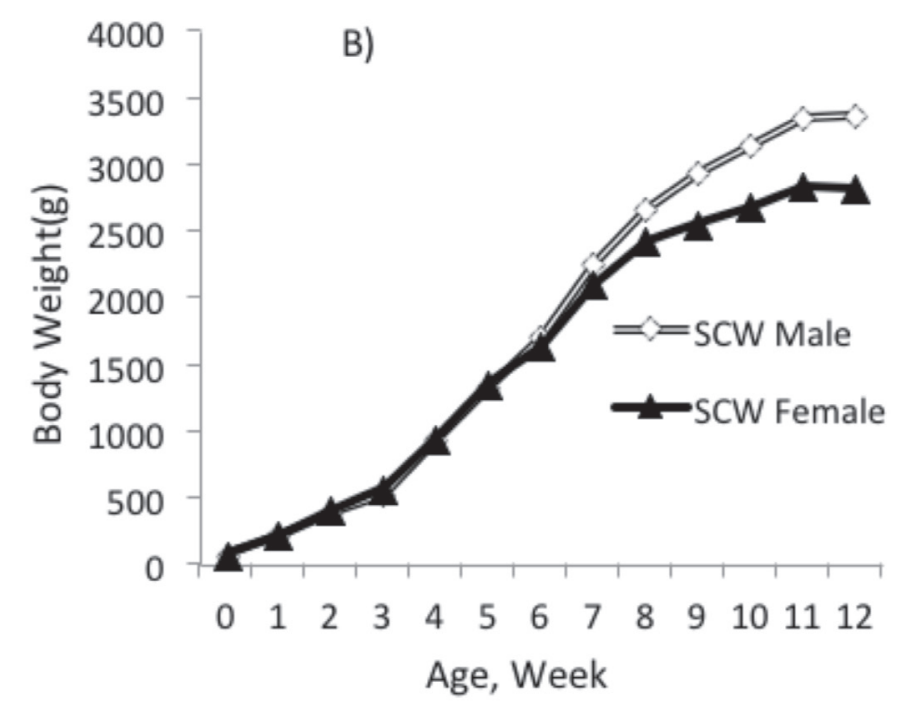

Figure $1-A=$ Cumulative growth curve of Shitou (ST), B=Cumulative growth curve of Sichuan White Goose (SCW)

A)

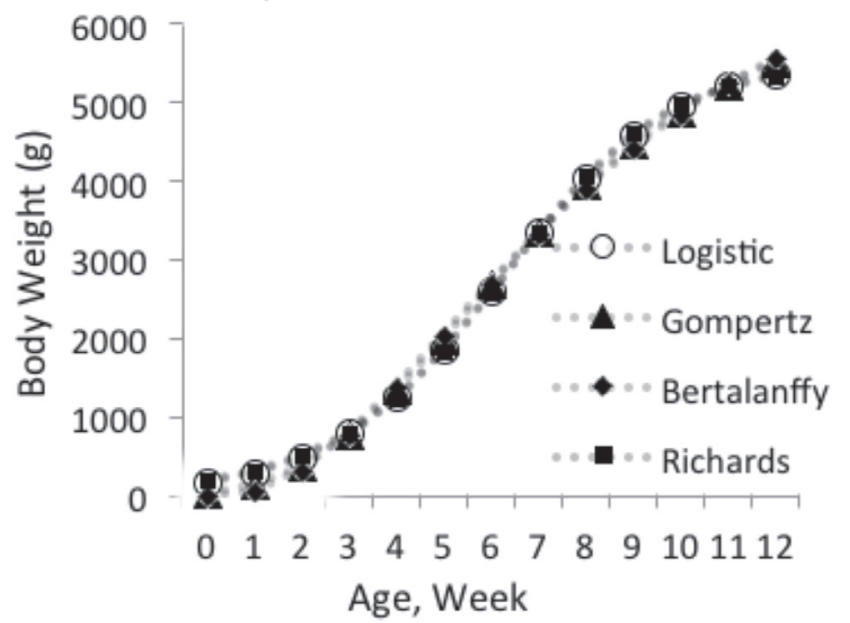

B)

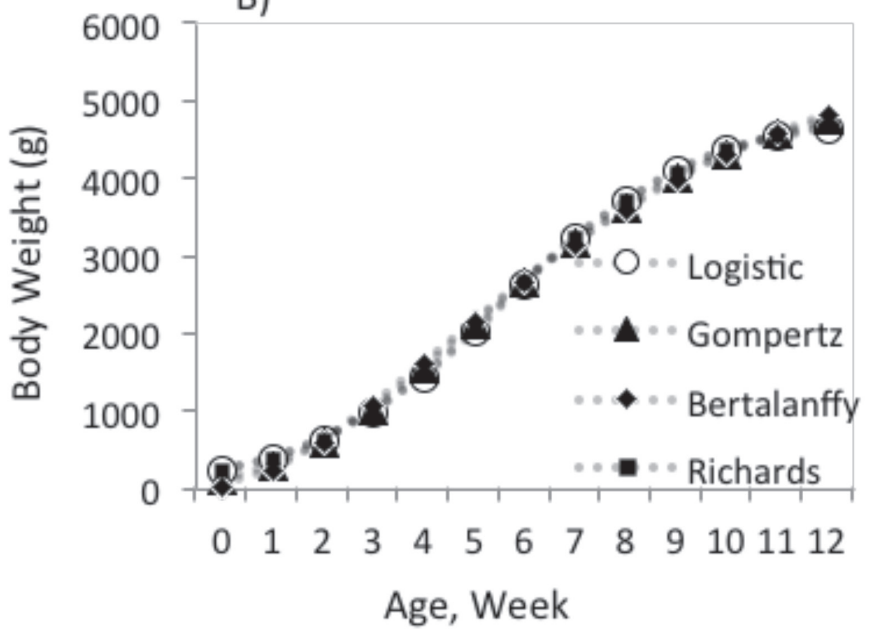

Figure $2-A=$ Growth Curve of ST male according to nonlinear models, B=Growth Curve of ST female according to nonlinear models 
A)

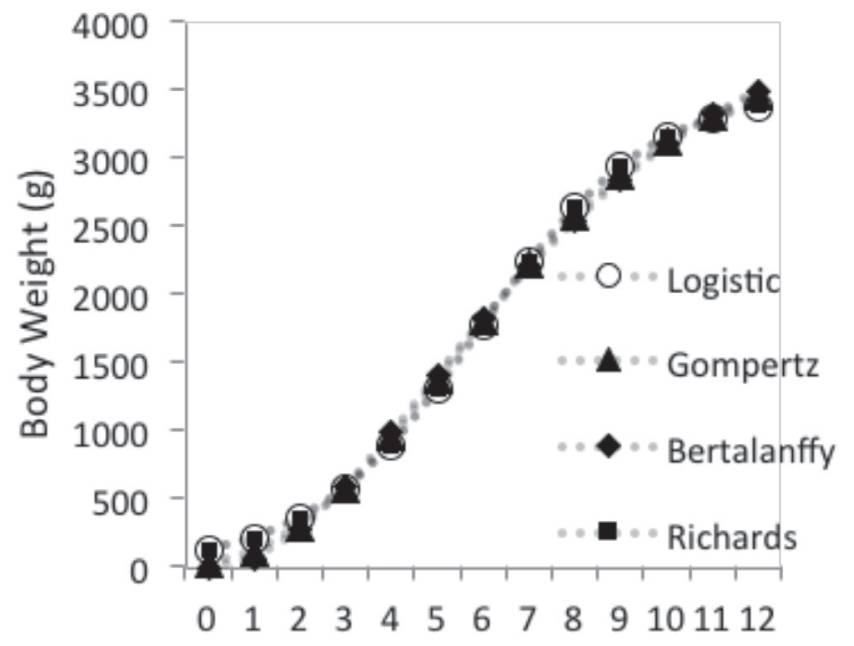

Age, Week
B)

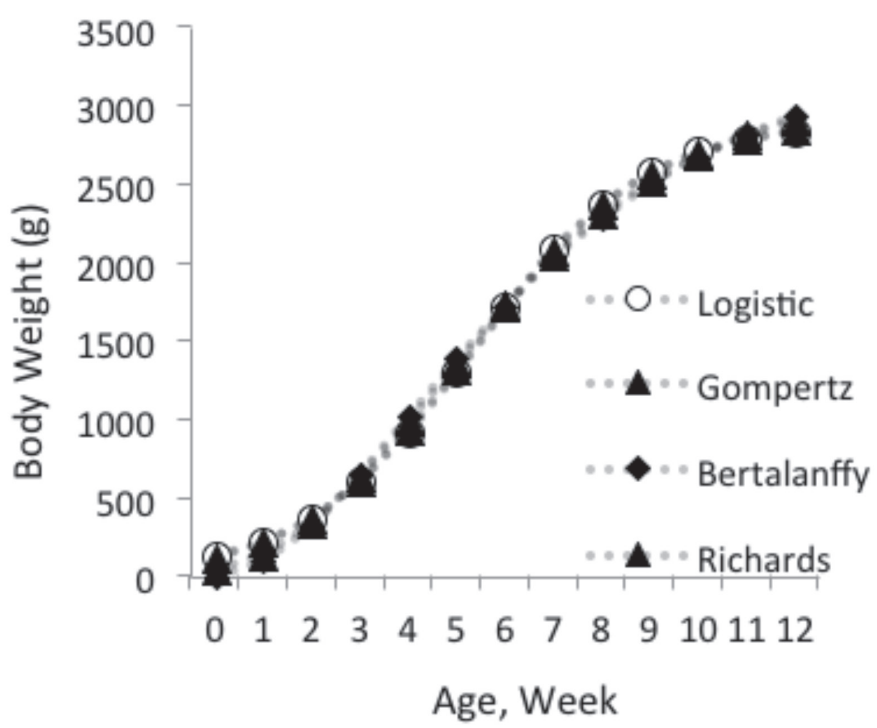

Figure 3-A=Growth Curve of SCW male according to nonlinear models, B=Growth Curve of SCW and female according to nonlinear models.

\section{Body Weight}

Actual and predicted weights of ST males are presented in Table 2 and female in Table 3. ST male weight was significantly $(p<0.05)$ higher than female at day 1 and from $1^{\text {st }}-12^{\text {th }}$ week male weight was very significant $(p<0.01)$, higher than the female. Actual and predicted weights of SCW males are presented

Table 2 - Comparisons between the observed values and the estimated values of four fitting curve models in ST Male Goose (g)

\begin{tabular}{|c|c|c|c|c|c|}
\hline Week & Observed Value & Logistic & Gompertz & Bertalanffy & Richards \\
\hline 0 & $114.98 \pm 7.38$ & 171.53 & 38.34 & 0.03 & 199.04 \\
\hline 1 & $323.21 \pm 30.17$ & 291.24 & 142.23 & 61.52 & 320.44 \\
\hline 2 & $549.26 \pm 78.57$ & 486.99 & 376.95 & 324.79 & 511.86 \\
\hline 3 & $765.73 \pm 136.26$ & 794.57 & 778.05 & 788.03 & 806.34 \\
\hline 4 & $1290.16 \pm 222.74$ & 1248.88 & 1333.54 & 1384.17 & 1240.31 \\
\hline 5 & $1904.26 \pm 238.56$ & 1862.05 & 1990.60 & 2041.22 & 1836.03 \\
\hline 6 & $2470.15 \pm 278.38$ & 2596.19 & 2681.25 & 2702.58 & 2570.5 \\
\hline 7 & $3342.05 \pm 289.96$ & 3358.92 & 3345.90 & 3330.47 & 3354.38 \\
\hline 8 & $4120.52 \pm 361.65$ & 4043.01 & 3944.76 & 3903.18 & 4063.05 \\
\hline 9 & $4588.89 \pm 381.76$ & 4580.27 & 4458.47 & 4410.85 & 4608.56 \\
\hline 10 & $4977.89 \pm 439.13$ & 4959.88 & 4883.32 & 4851.51 & 4976.65 \\
\hline 11 & $5222.1 \pm 543.13$ & 5208.50 & 5225.24 & 5228.03 & 5202.86 \\
\hline 12 & $5313.68 \pm 592.22$ & 5363.34 & 5494.88 & 5545.90 & 5333.83 \\
\hline
\end{tabular}

Table 3 - Comparison between observed value and estimated value of three fitting curve Models in ST Female Goose (g)

\begin{tabular}{|c|c|c|c|c|c|}
\hline Week & Observed Value & Logistic & Gompertz & Bertalanffy & Richards \\
\hline 0 & $105.71 \pm 5.45$ & 249.41 & 109.88 & 42.21 & 225.83 \\
\hline 1 & $363.05 \pm 21.10$ & 404.05 & 288.96 & 240.40 & 383.28 \\
\hline 2 & $737.57 \pm 49.85$ & 641.11 & 597.82 & 601.65 & 629.57 \\
\hline 3 & $998 \pm 36.27$ & 986.26 & 1032.67 & 1076.87 & 989.16 \\
\hline 4 & $1503.94 \pm 82.60$ & 1452.71 & 1557.60 & 1609.62 & 1468.96 \\
\hline 5 & $2022.16 \pm 111.33$ & 2023.51 & 2121.61 & 2153.68 & 2043.14 \\
\hline 6 & $2533.94 \pm 143.44$ & 2642.88 & 2676.56 & 2676.91 & 2652.70 \\
\hline 7 & $3254.94 \pm 212.34$ & 3233.13 & 3187.52 & 3159.83 & 3226.98 \\
\hline 8 & $3818.42 \pm 167.20$ & 3729.99 & 3634.98 & 3592.65 & 3712.77 \\
\hline 9 & $4100 \pm 163.84$ & 4106.37 & 4012.34 & 3972.26 & 4088.86 \\
\hline 10 & $4271.05 \pm 174.03$ & 4369.34 & 4321.67 & 4299.83 & 4360.99 \\
\hline 11 & $4576.77 \pm 95.56$ & 4542.85 & 4569.85 & 4578.99 & 4548.57 \\
\hline 12 & $4673.77 \pm 127.48$ & 4653.06 & 4765.81 & 4814.60 & 4673.65 \\
\hline
\end{tabular}


in Table 4 and female in Table 5. During the growth period from 0 to $5^{\text {th }}$ week there was no significant difference between the weights of SCW male and female. In $6^{\text {th }}$ and $12^{\text {th }}$ week the significant difference was $(p<0.05)$, but during $7^{\text {th }}-11^{\text {th }}$ weeks the difference between weights was very significant $(p<0.01)$.

Table 4 - Comparison between observed value and estimated value of three fitting curve Models in SCW Male Goose (g)

\begin{tabular}{llllll}
\hline Week & Observed Value & Logistic & Gompertz & Bertalanffy & Richards \\
\hline 0 & $79.78 \pm 11.81$ & 129.77 & 35.49 & 1.26 & 125.89 \\
1 & $222.47 \pm 19.64$ & 218.49 & 120.80 & 68.33 & 214.56 \\
2 & $392.28 \pm 60.37$ & 361.41 & 299.07 & 274.68 & 358.42 \\
3 & $540.53 \pm 95.61$ & 581.34 & 584.92 & 600.16 & 580.51 \\
4 & $935.58 \pm 151.57$ & 897.05 & 960.90 & 996.03 & 898.96 \\
5 & $1342.58 \pm 151.57$ & 1307.85 & 1387.44 & 1416.72 & 1311.39 \\
6 & $1707.32 \pm 172.48$ & 1779.03 & 1820.85 & 1829.01 & 1781.63 \\
7 & $2265.89 \pm 207.96$ & 2247.30 & 2226.58 & 2212.22 & 2247.01 \\
8 & $2677.89 \pm 231.59$ & 2650.85 & 2583.97 & 2555.64 & 2648.02 \\
9 & $2938.94 \pm 247.91$ & 2958.06 & 2884.90 & 2855.45 & 2954.77 \\
10 & $3153.68 \pm 267.06$ & 3170.58 & 3129.93 & 3112.18 & 3168.86 \\
11 & $3349.47 \pm 284.78$ & 3308.03 & 3324.55 & 3328.87 & 3308.93 \\
\hline
\end{tabular}

Table 5 - Comparison between observed value and estimated value of three fitting curve Models in SCW Female Goose (g)

\begin{tabular}{|c|c|c|c|c|c|}
\hline Week & Observed Value & Logistic & Gompertz & Bertalanffy & Richards \\
\hline 0 & $79.58 \pm 6.59$ & 133.47 & 43.12 & 5.08 & 12.92 \\
\hline 1 & $229.94 \pm 13.57$ & 227.50 & 143.10 & 99.95 & 218.48 \\
\hline 2 & $408.61 \pm 34.72$ & 378.72 & 339.76 & 331.37 & 373.14 \\
\hline 3 & $574.05 \pm 52.37$ & 607.67 & 633.65 & 657.94 & 608.28 \\
\hline 4 & $950.77 \pm 104.82$ & 924.37 & 992.99 & 1025.38 & 930.97 \\
\hline 5 & $1360.44 \pm 126.32$ & 1311.91 & 1372.69 & 1391.85 & 1319.73 \\
\hline 6 & $1641.01 \pm 140.48$ & 1720.80 & 1733.54 & 1731.64 & 1723.80 \\
\hline 7 & $2100.35 \pm 142.06$ & 2089.99 & 2051.14 & 2032.03 & 2086.28 \\
\hline 8 & $2425.29 \pm 152.64$ & 2379.32 & 2315.57 & 2289.04 & 2372.04 \\
\hline 9 & $2557.5 \pm 181.69$ & 2581.90 & 2527.06 & 2503.89 & 2575.68 \\
\hline 10 & $2681.25 \pm 189.69$ & 2712.81 & 2691.38 & 2680.48 & 2710.72 \\
\hline 11 & $2838.12 \pm 225.66$ & 2793.08 & 2816.41 & 2823.83 & 2796.09 \\
\hline 12 & $2825.5 \pm 232.10$ & 2840.72 & 2910.12 & 2939.12 & 2848.44 \\
\hline
\end{tabular}

\section{Model Parameters}

Four curves result analysis including estimated parameters, $\mathrm{R}^{2}$, and inflection points are represented in Table 6. Among all models Bertalanffy curve showed the lowest $R^{2}$ ranging from 0.992 to 0.994 . The equivalent range was 0.996 to 0.997 for the Gompertz curve and 0.998 to 0.999 for both logistic and Richards curves. So among all these models logistic and Richards were the best fit for the experimental data from the beginning to the end. In Richards model shape parameter (Table 6) were 1.289,0.946, 0.785, and 0.864 for ST male, female and SCW male, female, respectively. Furthermore, all nonlinear models showed that ST males and females had greater body weight at the inflection point as compared to SCW.

\section{DISCUSSION}

Variation in growth curves of different domestic species is predominantly related to the evolutionary differences between the wild ancestors of species. Many functions have been developed to deal with growth and new ones are continuously being proposed, Beiki et al. (2013). Understanding and estimating, the defining characteristics of growth processes are key components of developmental research. Growth curve is an effective tool for biological analysis, investigation and interpretation of growth relationships, Ramos et al. (2013). Nonlinear growth curves are essential for capturing these various change components like body weight, inflection point and parameter can easily be calculated by growth curve models, Nahashon et al. (2006). The simplest nonlinear models including logistic, Gompertz, Von Bertalanffy and Richards were used to study the goose growth. All these four functions can be well fitted with the growth curve of ST and SCW goose ( $\left.R^{2}>0.99\right)$, but further analyses of four kinds of model fitting parameters are listed in Table 6 . Logistic and Richards models had similar and higher $\mathrm{R}^{2}$ value than the other two models. 
Table 6 - The analysis results of four curves

\begin{tabular}{|c|c|c|c|c|c|c|c|c|c|}
\hline Sex & Model & Breed & $A$ & $B$ & k & $d$ & R2 & IPA & IPW \\
\hline \multirow[t]{8}{*}{ Male } & Logistic & ST & 5588.997 & 31.583 & 0.551 & & 0.999 & 6.254 & 2794.498 \\
\hline & & SCW & 3517.185 & 26.104 & 0.548 & & 0.999 & 5.952 & 1758.592 \\
\hline & Gompertz & ST & 6357.710 & 5.111 & 0.296 & & 0.996 & 5.511 & 2338.870 \\
\hline & & SCW & 3947.340 & 4.712 & 0.301 & & 0.997 & 5.149 & 1452.145 \\
\hline & Bertalanffy & ST & 7019.657 & 0.983 & 0.214 & & 0.992 & 5.053 & 2079.898 \\
\hline & & SCW & 4309.734 & 0.934 & 0.221 & & 0.994 & 4.662 & 1276.958 \\
\hline & Richards & ST & 5494.107 & 4.262 & 0.625 & 1.289 & 0.999 & 3.508 & 2889.910 \\
\hline & & SCW & 3529.109 & 3.112 & 0.534 & 0.946 & 0.999 & 4.100 & 1746.240 \\
\hline \multirow[t]{8}{*}{ Female } & Logistic & ST & 4826.101 & 18.35 & 0.517 & & 0.998 & 5.627 & 2413.050 \\
\hline & & SCW & 2905.548 & 20.770 & 0.568 & & 0.998 & 5.340 & 1452.774 \\
\hline & Gompertz & ST & 5412.485 & 3.897 & 0.285 & & 0.997 & 4.772 & 1991.141 \\
\hline & & SCW & 3166.698 & 4.296 & 0.327 & & 0.996 & 4.457 & 1164.963 \\
\hline & Bertalanffy & ST & 5931.887 & 0.808 & 0.207 & & 0.994 & 4.277 & 1757.596 \\
\hline & & SCW & 3372.866 & 0.885 & 0.249 & & 0.993 & 3.921 & 999.367 \\
\hline & Richards & ST & 4898.086 & 2.322 & 0.467 & 0.785 & 0.998 & 4.460 & 2341.734 \\
\hline & & SCW & 2925.590 & 2.665 & 0.535 & 0.864 & 0.998 & 3.970 & 1422.977 \\
\hline
\end{tabular}

ST: Shitou Goose; SCW: Sichuan White Goose; A: Maximum body weight; $\mathrm{k}$ : Transient growth rate; B: Parameter; t: Weekly age; $d$; Shape Parameter, R2 = coefficient of determination IPA = age (wk) at point of inflection; IPW: body weight ( $\mathrm{g}$ ) at point of inflection.

Inflection point is the fastest growth rate, after that the growth rate will gradually slow down. The inflection age, as the age at maximum instantaneous relative growth rate, can be used to predict the market age, Gao et al. (2013). Generally, the curve fitting of the geese weight-age data was poorer than in other species of poultry so our findings can be additional information on the growth pattern of geese. Inflection point of age and weight was different in all four models. According to optimal Logistic fitting model male ST inflection weight and inflection age were $2794.49 \mathrm{~g}$ and 6.25 weeks, respectively while in female it was $2413.05 \mathrm{~g}$ and 5.62 weeks and our result opposed the findings of Ye et al (Yehui \& Zhong, 2005) at inflection point in ST goose. Likely the inflection weight and age in male and female SCW were $1758.59 \mathrm{~g}$ and 5.95 weeks, $1452.77 \mathrm{~g}$ and 5.34 weeks respectively. While according to Richards inflection age of ST male, female and SCW male, female were 3.50, 4.10,4.46, and 3.97 week while weight at inflection were 2889.91, $1746.24,2341.73$ and 1422.97 grams respectively (Table 6). So it showed that ST breed got higher weight then the SCW breed and also the growth rate (Tables 3-5), was faster in ST than the SCW. According to logistic, Gompertz and Bertalanffy the female reached the inflection point faster than the male but in Richards that was opposite in which male reached the inflection point faster than the female; that was also reported by Sezer \& Tarhan (2005) in quail. That difference in inflection point could be due to Richards shape parameter (d), as it has greater propensity to change in response to environment, Wang et al. (2012).
In all models the $\mathrm{R}^{2}$ value of female was lower than the male, that could have been caused by higher fat accumulation during the later stages of growth and rapid development of sexual organs, Knízetová et al. (1994). The growth curve fitting not only described the growth mathematically, but also estimated the relationship between raising management and Body weight, which is beneficial to animal husbandry, Shi et al. (2010). However, almost all of the experimental goose change in body weight was very little after 9 weeks of age, implying that 9 weeks was the latest market age for meat type goose.

We found that Logistic and Richards goodness $\left(R^{2}\right)$ and " $A$ " parameter were higher than others. Richards model has variable points of inflection specified by the shape parameter " $d$ ". The Richards shape parameter (d) showed clear differences between the sexes and it was higher in males than the females, thus males reached inflection point more quickly than female. When shape parameter $(d)=0$, the model approximates the exponential growth function and when $d=0.67,1,2$, the model behaves like the von Bertalanffy, Gompertz, Logistic model, respectively, Marinakis (2012). Shape parameters estimated for ST male and female were close to 1, indicating that their growth curves look like Gompertz model. On the other hand, d parameters for SCW breed were between Gompertz and Bertalanffy models but the logistic predicted growth parameters were more closed to observed value then all remaining three models. So overall logistic was the best fitted model for the growth analysis of Chinese goose and 
results were in disagreement with the previous theory that stated Gompertz equation was the best fit for the goose (Hua-Li et al., 2011; Chen et al., 2014).

\section{CONCLUSION}

Exploring the growth characteristics of goose will contribute to the efforts of genetically improving this little-studied avian species. All four models can be used to analyze the growth of the goose but due to having three parameters, using logistic, Gompertz and Bertalanffy are easier and more reliable than the Richards, but Logistic model is good predictors of growth patterns in goose according to our findings. Shitou goose has better growth performance than the Sichuan White goose. According to the growth curve after nine weeks growth rate was very slow, it suggests that the time of coming onto the market for the goose should be before nine weeks old.

\section{CONFLICTS OF INTEREST}

The authors declare no conflicts of interest.

\section{ACKNOWLEDGEMENTS}

This work was supported by the Foundation of Zhanjiang Science and Technology Bureau (B06135) and the Co-operative Foundation between the Guangdong Ocean University and Enterprise (B15337).

\section{REFERENCES}

Aggrey SE. Comparison of three nonlinear and spline regression models for describing chicken growth curves. Poultry Science 2002;81:17821788. DOI:10.1093/ps/81.12.1782

Beiki H, Pakdel A, Moradi-shahrbabak M, Mehrban H. Evaluation of growth functions on japanese quail lines. The Journal of Poultry Science 2013;50:20-27. DOI:10.2141/jpsa.0110142

Chen Y, Huang ZY, Zhang Y, Qi XU, Wang DD, Chen G.H. Comparative analysis on growth curve fitting of three types of goose. Chinese Journal of Animal Science 2014;50:6-9.

Darmani Kuhi $H$, Porter T, Lopez S, Kebreab E, Strathe AB, et al. A review of mathematical functions for the analysis of growth in poultry. World's Poultry Science Journal 2010;66:227-240. Doi:10.1017/ S0043933910000280

Ding N, Han Q, Li Q, Zhao X, Li J, Su J, et al. Comprehensive analysis of Sichuan white geese (Anser cygnoides) transcriptome. Animal Science Journal 2014;85:650-659. DOI:10.1111/asj.12197

Gang FY, Zhen YS. A study on the growth curve of and maximum profit from layer-type cockerel chicks. British Poultry Science 1997;38:445446. DOI:10.1080/00071669708418019

Gao CQ, Yang JX, Chen MX, Yan HC, Wang XQ. Growth curves and agerelated changes in carcass characteristics, organs, serum parameters, and intestinal transporter gene expression in domestic pigeon (Columba livia). Poultry Science 2016;95(4):867-877. DOI:10.3382/ps/pev443
Geng T, Zhao X, Xia L, Liu L, Li F, Yang B, et al. Supplementing dietary sugar promotes endoplasmic reticulum stress-independent insulin resistance and fatty liver in goose. Biochemical and Biophysical Research Communications 2016;476(4):665-669. DOI:10.1016/j. bbrc.2016.05.149

Grimm KJ, Ram N, Hamagami F. Nonlinear growth curves in developmental research. Child Development 2011;82:1357-1371. Doi:10.1111/ j.1467-8624.2011.01630.x

Hua-Li WU, Zhou B, Wang HY, Liu Y, Yao-Dong HU, Zhu Q, et al. Analyze on growth curve fitting of zhejiang white goose. China Animal Husbandry \& Veterinary Medicine 2011; 38(5):134-137.

Kim SJ, Lee KW, Kang CW, An BK. Growth performance, relative meat and organ weights, cecal microflora, and blood characteristics in broiler chickens fed diets containing different nutrient density with or without essential oils. Asian-Australasian Journal of Animal Ssciences 2016;29:549-554. Doi:10.5713/ajas.15.0426

Knízetová H, Hyánek J, Hyánková L, Belicek P. Comparative study of growth in poultry curves. Genetic Selection Evolution 1995;27:365-375.

Knízetová H, Hyánek J, Kníze B, Roubícek J. Analysis of growth curves of fowl. I. chickens. British Poultry Science 1994;35:335-344. DOI:10.1080/00071669108417427

Lin M.J, Chang S.C, Jea Y.S, Chen W.S, Lee T.T. Effects of dietary garlic scape meal on the growth and meat characteristics of geese. British Poultry Science 2015;56:716-722. DOI:10.1080/00071668.2015.109 6012

Liu W, Tang S, Xiao Y. Model selection and evaluation based on emerging infectious disease data sets including $\mathrm{A} / \mathrm{H} 1 \mathrm{~N} 1$ and ebola. Computational and Mathematical Methods in Medicine 2015:207105. doi:10.1155/2015/207105

Marinakis Y.D. Forecasting technology diffusion with the Richards model. Technological Forecasting and Social Change 2012;79:172-179. DOI:10.1016/j.techfore.2011.02.010

Mignon-Grasteau S, Beaumont C, Le Bihan-Duval E, Poivey JP, Rochambeau $\mathrm{H}$, Ricard FH. Genetic parameters of growth curve parameters in male and female chickens. British Poultry Science 1999;40:44-51. Doi:10.1080/00071669987827

Nahashon SN, Aggrey SE, Adefope N, Amenyenu A, Wright D. Growth characteristics of pearl gray guinea fowl as predicted by the Richards, Gompertz, and logistic models. Poultry science 2006;85:359-363.

Ramos SB, Caetano SL, Savegnago RP, Nunes BN, Ramos AA, Munari DP. Growth curves for ostriches (Struthio camelus) in a Brazilian population. Poultry Science 2013;92:277-282. DOI:10.3382/ps.2012-02380

Rizzi C, Contiero B, Cassandro M. Growth patterns of Italian local chicken populations. Poultry Science 2013;92:2226-2235. Doi:10.3382/ ps.2012-02825

Schofield MR, Barker RJ, Taylor P. Modeling individual specific fish length from capture-recapture data using the von Bertalanffy growth curve. Biometrics 2013;69:1012-1021. DOl:10.1111/biom.12069

Şengül T, Kiraz S. Non-Linear models for growth curves in large white turkeys. Turkish Journal of Veterinary and Animal Science 2005;29:331-337.

Sezer M, Tarhan S. Model parameters of growth curves of three meat-type lines of Japanese quail. Czech Journal of Animal Science 2005:22-30.

Shi SR, Wang ZY, Zou JM, Yang HM, Jiang N. Effects of dietary threonine on growth performance and carcass traits of Yangzhou geese. Czech Journal of Animal Science 2010;55:382-387.

Stevenson H, Bly B, Stevenson H. Nutrition of domestic geese. Proceedings of the Nutrition Society 1989:103-111.

Wang XS, Wu J, Yang Y. Richards model revisited: validation by and application to infection dynamics. Journal of Theoretical Biology 2012;313:12-19. DOI:10.1016/j.jtbi.2012.07.024

Ye $\mathrm{CH}$, Zhong RC. Studies on growth model of shitou goose. Journal of Shihezi University (Natural Science) 2005;23:4-8.

Zhu W, Chen K, Li H, Song W, Xu W, Shu J, et al. Two maternal origins of the Chinese domestic grey goose. Journal of Animal and Veterinary Advances 2010;9:2674-2678. DOI:10.3923/javaa.2010.2674.2678 
